\title{
Study of hydrogen bonding and solvent polarity effects on the nitrogen NMR shieldings of $N, N$-dimethylacetamidine
}

\author{
Michal Witanowski, ${ }^{1 *}$ Wanda Sicinska, ${ }^{1}$ Zenobia Biedrzycka ${ }^{1}$ and Graham A. Webb ${ }^{2}$ \\ ${ }^{1}$ Institute of Organic Chemistry, Polish Academy of Sciences, 01-224 Warsaw, Poland \\ 2 Department of Chemistry, University of Surrey, Guildford, Surrey GU2 5XH, UK
}

Received 16 July 1999; revised 26 October 1999; accepted 29 October 1999

\begin{abstract}
Solvent effects on the nitrogen shieldings of $N, N$-dimethylacetamidine (1) were found to be extremely large for the imino group (about $120 \mathrm{ppm}$ ) and for the amino moiety (about $50 \mathrm{ppm}$ ). A detailed analysis of the solvent-induced variations revealed contributions from three large interactions. These are due to solvent polarity, hydrogen bonding from solute to solvent, via the NH moiety of the solute, and from solvent to solute, involving the nitrogen lone pairs of the solute. For the imino moiety, large shielding effects are observed due to solvent polarity and solvent-to-solute hydrogen bonding, whereas solute-to solvent hydrogen bonding leads to a large decrease in nitrogen shielding. For the $\mathrm{NMe}_{2}$ group, the changes are of opposite sign and smaller in magnitude. Ab initio CHF-GIAO magnetic shielding calculations employing a $6-31++\mathrm{G}^{* *}$ basis set and geometries optimized using the same basis set are reported for $\mathbf{1}$ and some related molecules. The experimental range of nitrogen shielding considered is about $270 \mathrm{ppm}$ and shows an excellent linear correlation with the calculated results. The least-squares standard deviation amounts to only $1.7 \%$ of the observed shielding range. The effects on the nitrogen shielding of 1 caused by full protonation are accurately reproduced within this correlation. Copyright $\odot 2000$ John Wiley \& Sons, Ltd.
\end{abstract}

KEYWORDS: NMR; ${ }^{14} \mathrm{~N}$ NMR; amidines; nitrogen shieldings; nitrogen chemical shifts; solvent effects; ab initio calculations

\section{INTRODUCTION}

Amidine systems are structural analogues of amides in which the amido carbonyl group is replaced by an imino moiety (Scheme 1). Hence there are two types of nitrogen atoms present in amidine systems, imino and amido (or amino) type. The lone pair electrons of the latter can be delocalised as shown by the conventional resonance structures presented in Scheme 2. This situation is comparable to that with amides. However, in contrast to amides, amidines are strong bases. For example, Fourier transform ion cyclotron resonance spectrometry of the parent acetamidine gives a gas-phase proton affinity of $962.7 \mathrm{~kJ} \mathrm{~mol}^{-1}{ }^{1}$ In the case of various alkylsubstituted formamidines, $\mathrm{p} K_{\mathrm{a}}$ values of about 9 have been measured, ${ }^{2}$ and $\mathrm{p} K_{\mathrm{a}}$ values of about 13 have been reported for some $N, N^{\prime}$-disubstituted amidines. ${ }^{3}$ As shown by the resonance structures in Scheme 2, rotation around the $\mathrm{C}-\mathrm{NR}_{2}$ bond is restricted, the barrier being about $50-60 \mathrm{~kJ} \mathrm{~mol}^{-1}\left({ }^{13} \mathrm{C}\right.$ NMR measurements). ${ }^{4}$ Concerning hydrogen bonding, amidines act as strong acceptors. In the presence of 4-fluorophenol in $\mathrm{CCl}_{4}$ as a standard hydrogen bond donor, $\log K_{\mathrm{HB}}$ values of about 1.2-1.7 have been reported for various amidines. ${ }^{5}$ Similarly, when acetic acid is used as a hydrogen bond donor, a variety of amidines give $\log K_{\mathrm{HB}}$ values of about $3 .^{6}$

In view of these observations, it is of interest to perform precise ${ }^{14} \mathrm{~N}$ NMR measurements of solvent-induced

* Correspondence to: M. Witanowski, Institute of Organic Chemistry, Polish Academy of Sciences, 01-224 Warsaw, Poland. effects on the nitrogen shieldings of a model amidine system. The chosen model is $N, N$-dimethylacetamidine (1, shown in Scheme 1). By this choice we avoid complications which may result from prototropic tautomerization, which includes the migration of hydrogen atoms between the two nitrogenous sites in the molecule. We also avoid potential complications which could arise from isomerization resulting from rotation around the $\mathrm{C}-\mathrm{NR}_{2}$ bond if the two R groups were different.

Previously, we have reported the effects of solvents on the NMR shieldings of nitrogen atoms in various structural types which resemble amidines, in that they contain either or both types of nitrogen atoms found in amidine systems. These include acetone- $N$-methylimine, ${ }^{7}$ aromatic imino systems (azine heteroaromatics), ${ }^{8,9}$ azole ring systems ${ }^{10-13}$ and isoamides (amidates). ${ }^{14}$ From our experience, we can anticipate the behaviour of amidine nitrogen NMR shieldings as a function of solute-solvent interactions as depicted in Scheme 3. Increasing the solvent polarity results in an enhanced delocalization of the lone pair electrons from the $\mathrm{NR}_{2}$ group to the imino moiety, and this should result in an increase of the nitrogen shielding of the $=\mathrm{NH}$ nitrogen and a decrease for the $\mathrm{NR}_{2}$ nitrogen. Solvent-to-solute hydrogen bonding to the imino nitrogen atom should result in an analogous enhancement of lone pair delocalization from the $\mathrm{NR}_{2}$ group. This delocalization in combination with the engagement of the imino nitrogen lone-pair electrons in the hydrogen bonding to the solvent should yield substantial increase in the imino nitrogen shielding. This should be accompanied by 
<smiles>CC(=N)N(C)C</smiles>

N,N-dimethylacetamidine 1<smiles></smiles>

Z-isomer

1a<smiles>CC(=N)N(C)C</smiles>

E-isomer
Scheme 1. Structure of 1 and its possible geometric isomers $\mathbf{1 a}$ and $\mathbf{1 b}$. Ab initio calculated energies and a comparison of calculated and experimental nitrogen shieldings indicate that the content of $1 \mathrm{a}$ is negligible.

a moderate decrease in the nitrogen shielding of the $\mathrm{NR}_{2}$ moiety. In contrast, solute-to-solvent hydrogen bonding, where the imino $=\mathrm{NH}$ moiety is involved as a hydrogen bond donor, renders effects on the nitrogen shieldings in the opposite directions to those considered above, i.e. the imino nitrogen shielding is expected to decrease and that of the $\mathrm{NR}_{2}$ nitrogen to increase.

Consequently, our choice of $N, N$-dimethylacetamidine (1) as a model enables us to study the potentially complex behaviour of nitrogen shieldings under the influence of solvents, provided that the choice of solvents used represents a wide range of properties such as polarity and hydrogen bond acceptor and donor strengths. In view of the high basicity of amidine systems, we expect that such effects on nitrogen shieldings should be significant and<smiles>[R][N+]([R])=C(C)[NH-]</smiles>

Scheme 2. Conventional resonance structures that depict $\pi$-electron delocalization in amidine systems.

are likely to surpass in magnitude those found in other nitrogen analogues.

In common with our earlier reports, ${ }^{7-15}$ we present our results in terms of $\Delta \sigma$, which represents the differences in the nitrogen nuclear shielding constants $\sigma$ of the compound studied and that of neat liquid nitromethane used as external reference, with corrections for bulk magnetic susceptibility differences. Thus we use the expression 'nitrogen shielding' for $\Delta \sigma$, since a positive sign corresponds to an increase in magnetic shielding. Hence $\Delta \sigma=-\delta$, where the latter is commonly termed the chemical shift. Consequently, 'nitrogen shieldings' and 'nitrogen chemical shifts' differ only in their sign.

\section{RESULTS AND DISCUSSION}

Solvent effects on the nitrogen NMR shieldings of $N, N$ dimethylacetamidine, for a wide range of solvents, are reported in Table 1.

The methods used to produce the data given in Table 1 are described in the experimental section. The NMR shielding results are corrected for magnetic bulk susceptibility effects and have a precision such that only the final digit given is uncertain. From Table 1, we note that the range of shieldings for both types of nitrogen atoms in $\mathbf{1}$, as a function of solvent, is extremely large. This range surpasses anything found in our earlier studies ${ }^{7-15}$ on analogous nitrogen environments. For the imino moiety, the nitrogen shielding range is about $120 \mathrm{ppm}$, and

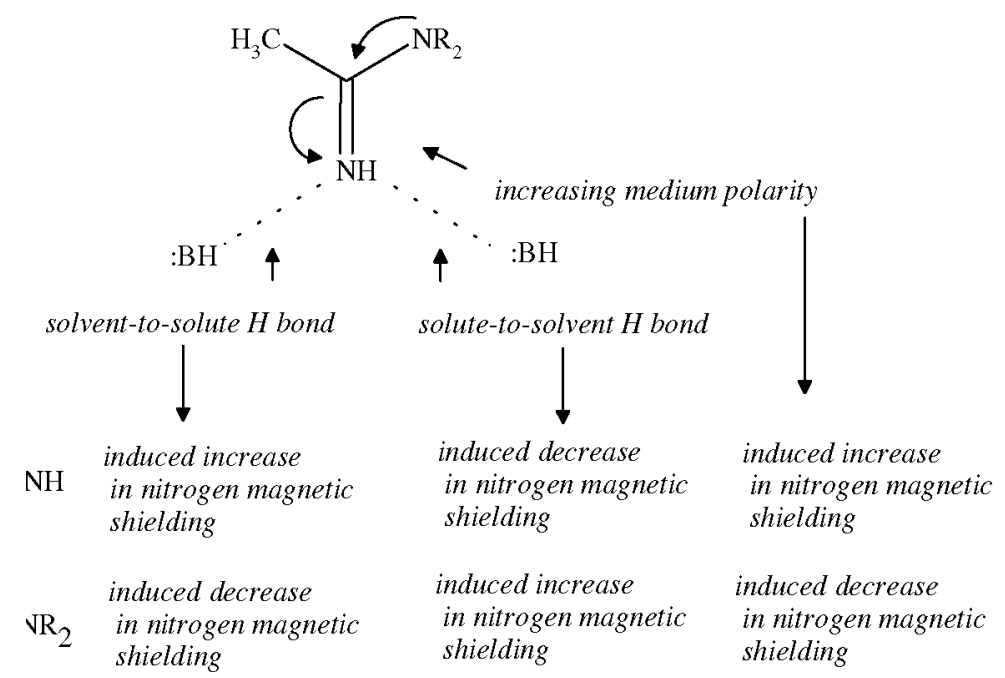

Scheme 3. Summary of solvent polarity and hydrogen bond effects on the nitrogen shielding of 1. 
Table 1. Solvent effects on the nitrogen NMR shieldings of $N, N$-dimethylacetamidine (1)

\begin{tabular}{llc}
\hline & \multicolumn{2}{c}{$\begin{array}{c}\text { Nitrogen NMR shielding (ppm) } \\
\text { referred to neat liquid nitromethane }\end{array}$} \\
\cline { 2 - 3 } Solvent & $=\mathrm{NH}$ & $-\mathrm{NMe}_{2}$ \\
\hline Cyclohexane & +157.81 & +311.14 \\
$\mathrm{Et}_{2} \mathrm{O}\left(30^{\circ} \mathrm{C}\right)$ & +160.71 & +311.13 \\
$\mathrm{CCl}_{4}$ & +161.53 & +310.01 \\
Benzene & +164.00 & +309.78 \\
Dioxane & +164.32 & +308.89 \\
Acetone & +166.41 & +308.92 \\
DMSO & +165.42 & +307.64 \\
$\mathrm{CH}_{2} \mathrm{Cl}$ & +175.47 & +305.64 \\
$\mathrm{CHCl}_{3}$ & +179.82 & +305.65 \\
$\mathrm{EtOH}$ & +191.03 & +302.50 \\
$\mathrm{MeOH}$ & +214.60 & +294.93 \\
$\mathrm{H}_{2} \mathrm{O}$ & $+276.06^{\mathrm{b}}$ & $+260.51^{\mathrm{b}}$ \\
$\mathrm{CF}_{3} \mathrm{CH}_{2} \mathrm{OH}$ & $+275^{\mathrm{b}}$ & $+275^{\mathrm{b}}$ \\
\hline
\end{tabular}

a All data are corrected for bulk susceptibility effects and related to $0.05 \mathrm{M}$ solutions at $35 \pm 0.2{ }^{\circ} \mathrm{C}$, if not stated otherwise.

$\mathrm{b}$ These shieldings indicate that a full transfer of a proton takes place from the solvent concerned to the $=\mathrm{NH}$ moiety.

for the amido moiety the range covers about $35 \mathrm{ppm}$. As the polarity and hydrogen bond donor strength of the chosen solvent increase, the imino nitrogen experiences a substantial increase in magnetic shielding whereas a smaller decrease in shielding occurs for the amido nitrogen. For water and $\mathrm{CF}_{3} \mathrm{CH}_{2} \mathrm{OH}$ as solvents the shieldings of the two nitrogen moieties are close to each other, showing that protonation of $\mathbf{1}$ occurs. If the solutions in these two solvents are ignored, the shielding range of the imino nitrogen in the other solvents considered is still $57 \mathrm{ppm}$, and that for the amido nitrogen is $17 \mathrm{ppm}$, which is beyond the ranges observed for analogous nitrogen environments studied previously. For example, in the case of the imino moiety in acetone- $N$-methylimine ${ }^{7}$ the analogous full shielding range is $47 \mathrm{ppm}$, and in the absence of solutions in water and $\mathrm{CF}_{3} \mathrm{CH}_{2} \mathrm{OH}$ the range is $28 \mathrm{ppm}$. For pyridine and other azine systems, ${ }^{8,9}$ the nitrogen nuclear shielding range in the full set of solvents does not exceed $47 \mathrm{ppm}$, and in the absence of water and $\mathrm{CF}_{3} \mathrm{CH}_{2} \mathrm{OH}$ as solvents the range is less than $30 \mathrm{ppm}$. The same applies to the imino nitrogen of $\alpha$-iminoethers (isoamides, amidates). ${ }^{14}$

Turning to the range of nitrogen shieldings experienced by the amido nitrogen (Table 1) as a function of solvent, we note that it is much larger than in analogous systems. For example, in $N$-methylpyrrole ${ }^{10}$ the range of nitrogen shieldings for the full set of solvents is $9 \mathrm{ppm}$, and $6 \mathrm{ppm}$ for the reduced solvent set. For pyrrole-type nitrogen atoms in azole systems ${ }^{11-13}$ the range of nitrogen shielding variations as a function of solvent does not exceed that of $N$-methylpyrrole.

Hence the predictions based on Scheme 3 are correct with respect to both the magnitude and sign of the change in nitrogen shielding as a function of solvent. In order to estimate the extent of the various contributions to the induced nitrogen shielding variations, a more detailed analysis is required. To achieve this we use the master Eqn (1) to separate the various specific and non-specific solvent-induced effects on the nitrogen shieldings: ${ }^{16,17}$

$$
\begin{aligned}
\sigma(i, j)= & \sigma_{0}(i)+a(i) \alpha(j)+b(i) \beta(j) \\
& +s(i)\left[\pi^{*}(j)+d(i) \delta(j)\right]
\end{aligned}
$$

where $i$ and $j$ represent the solute and solvent, respectively, $\alpha$ is the hydrogen bond donor strength of the solvent, $\beta$ is the solvent hydrogen bond acceptor strength, $\pi^{*}$ is the solvent polarity/polarizability and $\delta$ is a correction for aromatic solvents $(\delta=1)$ and polychlorinated solvents $(\delta=0.5)$. The solute terms $a, b, s$ and $d$ give the corresponding response of the solute nitrogen shielding to a given solvent property. The term $\sigma_{0}(i)$ gives the nitrogen shielding for the solute in a cyclohexane solution taken as a reference state. In Table 2 we report the solvent parameters used in conjunction with Eqn (1) and the least-squares fitted solute parameters for a set of master Eqns (1). As shown in Table 2, the values obtained for the parameter $d$ are insignificant for both nitrogen environments studied. In contrast, the other parameters, $a, b$ and $s$, are fairly large for both nitrogen atoms, and their signs are in accordance with the predictions given in Scheme 3 .

We note from Table 2 that solvent polarity and solventto-solute hydrogen bonding effects produce a large shielding increase for the imino nitrogen atom and a significant decrease in the shielding of the amido nitrogen atom. In contrast, solute-to-solvent hydrogen bonding, where the imino $\mathrm{NH}$ group acts as a donor, produces a large but opposite effect, namely deshielding for the imino nitrogen and an increase in the shielding for the $\mathrm{NMe}_{2}$ nitrogen atom. The largest of the fitted parameters given in Table 2 is the $a$ term of the imino nitrogen, which has a value of $+61 \mathrm{ppm} / \mathrm{unit}$ scale and corresponds to the nitrogen shielding response to the hydrogen bond donor strength of the solvent. The solvent parameter corresponding to $a$ is $\alpha$, which ranges from 0 to 1.51 (Table 2). Hence the solvent-to-solute hydrogen bonding interaction produces a contribution of up to about $+90 \mathrm{ppm}$ to the overall range of the imino nitrogen shielding variation introduced by the range of solvents studied. This is significantly greater than observed earlier ${ }^{7-14}$ for analogous nitrogen environments and covers about $75 \%$ of the total nitrogen shielding variation observed in the present work.

The effects of solvent polarity on the imino nitrogen atom are represented by the $s$ term, $+34 \mathrm{ppm} / \mathrm{unit}$ scale, and this corresponds to a contribution of up to $+37 \mathrm{ppm}$ to the total nitrogen shielding range observed. Thus the contribution is about one third of the nitrogen shielding variation reported in Table 1 . This contribution is at least twice as large as that found for nitrogen atoms in analogous environments. ${ }^{7-14}$ Similar comments apply to the term $b$ for the imino nitrogen, which represents the effects on the nitrogen shielding of hydrogen bond formation from the imino $\mathrm{NH}$ group to the solvent. Its magnitude is comparable to that of $s$, but its sign is opposite, corresponding to a deshielding of the imino nitrogen atom. Following this, the effects relating to the parameters $b$ and $s$ largely cancel each other, e.g. in the 
Table 2. Solvent parameters used and least-squares-fitted solute parameters for a set of master Eqns (1)

\begin{tabular}{|c|c|c|c|c|c|c|c|}
\hline Solvent & & $\alpha$ & & $\beta$ & $\pi^{*}$ & $\delta$ & $\begin{array}{l}\text { Dielectric } \\
\text { constant }\end{array}$ \\
\hline Cyclohexane & & 0 & & 0 & 0 & 0 & 1.87 \\
\hline $\mathrm{Et}_{2} \mathrm{O}$ & & 0 & & 0.47 & 0.27 & 0 & 3.89 \\
\hline $\mathrm{CCl}_{4}$ & & 0 & & 0 & 0.29 & 0.5 & 2.21 \\
\hline Benzene & & 0 & & 0.10 & 0.59 & 1 & 2.25 \\
\hline Dioxane & & 0 & & 0.37 & 0.55 & 0 & 2.19 \\
\hline Acetone & & 0.07 & & 0.48 & 0.72 & 0 & 19.75 \\
\hline DMSO & & 0 & & 0.76 & 1.00 & 0 & 45.80 \\
\hline $\mathrm{CH}_{2} \mathrm{Cl}_{2}$ & & 0.22 & & 0 & 0.80 & 0.5 & 8.54 \\
\hline $\mathrm{CHCl}_{3}$ & & 0.34 & & 0 & 0.76 & 0.5 & 4.55 \\
\hline $\mathrm{EtOH}$ & & 0.86 & & 0.77 & 0.54 & 0 & 24.20 \\
\hline $\mathrm{MeOH}$ & & 0.98 & & 0.62 & 0.60 & 0 & 30.71 \\
\hline $\mathrm{H}_{2} \mathrm{O}$ & & 1.13 & & 0.18 & 1.09 & 0 & 76.70 \\
\hline $\mathrm{CF}_{3} \mathrm{CH}_{2} \mathrm{OH}$ & & 1.51 & & 0 & 0.73 & 0 & - \\
\hline Moiety & $\begin{array}{c}\sigma_{0} \\
(\mathrm{ppm})\end{array}$ & & $\begin{array}{c}a \\
\text { (ppm/unit } \\
\text { scale) }\end{array}$ & $\begin{array}{c}b \\
\text { (ppm/unit } \\
\text { scale) }\end{array}$ & $\begin{array}{c}s \\
\text { (ppm/unit } \\
\text { scale) }\end{array}$ & $\begin{array}{c}d \\
\text { (dimension } \\
\text { less) }\end{array}$ & $\begin{array}{c}\text { Correlation } \\
\text { coefficient, } \\
r\end{array}$ \\
\hline$=\mathrm{NH}$ & $+159 \pm 9$ & & $+61 \pm 8$ & $-34 \pm 13$ & $+34 \pm 13$ & $-0.7 \pm 0.5$ & 0.93 \\
\hline$-\mathrm{NMe}_{2}$ & $+312 \pm 5$ & & $-19 \pm 5$ & $+18 \pm 8$ & $-19 \pm 8$ & $-0.7 \pm 0.4$ & 0.93 \\
\hline
\end{tabular}

a The constants were recalculated for a temperature of $35^{\circ} \mathrm{C}$ from the data available in Ref. 18 .

case of DMSO as a solvent where the corresponding solvent parameters are $\beta=0.76$ and $\pi^{*}=1.00$ (Table 2).

Considering the relevant solvent parameters $s$, DMSO as a solvent should shift the resonance of the imino nitrogen by about $+34 \mathrm{ppm}$ with respect to cyclohexane, i.e. in the direction of increased shielding. However, the observed shielding difference for the imino nitrogen atom for solutions in these two solvents is only about $+7 \mathrm{ppm}$. As noted from the value of $\beta=0.76$ (Table 2), DMSO is a strong acceptor of hydrogen bonds from the solute. Thus the concomitant effect on the nitrogen shielding amounts to about $-26 \mathrm{ppm}$, i.e. in the deshielding direction. Hence the solvent polarity and solute-to-solvent hydrogen bonding effects on the shielding of the imino nitrogen largely cancel each other in this case. The resultant is a small prevalence of the solvent polarity effect. Since $\alpha=0$ for DMSO, the possibility of solvent-to-solute hydrogen bond formation does not exist in this case.

An interesting example, where effects augment each other, is $\mathrm{CF}_{3} \mathrm{CH}_{2} \mathrm{OH}$ with respect to cyclohexane as solvent. As a bulk medium $\mathrm{CF}_{3} \mathrm{CH}_{2} \mathrm{OH}$ does not reveal any affinity to accept hydrogen bonds from a solute, $\beta=0$ in Table 2. This does not imply that $\mathrm{CF}_{3} \mathrm{CH}_{2} \mathrm{OH}$ is not a hydrogen bond acceptor on the molecular level. In reality, molecules of $\mathrm{CF}_{3} \mathrm{CH}_{2} \mathrm{OH}$ are strongly hydrogen bonded to each other. Consequently, molecules of $\mathrm{CF}_{3} \mathrm{CH}_{2} \mathrm{OH}$ prefer to be hydrogen bonded to each other and virtually none of their acceptor strength is left for the solute molecules concerned. Hence the actual hydrogen bond acceptor strength of $\mathrm{CF}_{3} \mathrm{CH}_{2} \mathrm{OH}$ with respect to solutes is essentially zero. As a result, only two of the solvent contributions considered are observed in the shielding variation of the imino nitrogen atom, about $+92 \mathrm{ppm}$ from solventto-solute hydrogen bonding and about $+24 \mathrm{ppm}$ from
$\mathrm{CF}_{3} \mathrm{CH}_{2} \mathrm{OH}$ polarity effects. Since these two effects augment each other, the observed nitrogen shielding change should amount to about $+116 \mathrm{ppm}$ as observed.

Turning now to consideration of the nitrogen shielding of the amido moiety, the overall solvent effects are much smaller than those found for the imino nitrogen. However, they are significant and their signs are opposite to the corresponding parameter values found for the imino nitrogen (Table 2). The three parameters $a, b$ and $s$ are about equal in magnitude whereas $b$ and $s$ and also $b$ and $a$ have opposite signs. Hence the overall situation resembles that for the imino moiety, except for the fact that the signs of the three terms are the opposite of those of their counterparts for the imino group. Again in the case of DMSO as a solvent, the resultant effect is about $-4 \mathrm{ppm}$ on the nitrogen shielding of $\mathrm{NMe}_{2}$. This is a result of the almost complete cancellation of two much larger contributions, about $-19 \mathrm{ppm}$ from solvent polarity and about $+15 \mathrm{ppm}$ for solute-to-solvent hydrogen bonding. In the case of $\mathrm{CF}_{3} \mathrm{CH}_{2} \mathrm{OH}$ as a solvent there are only two contributions to the nitrogen shielding variation of the $\mathrm{NMe}_{2}$ group, i.e. solvent polarity and solvent hydrogen bond donor strength. These augment each other and produce a substantial deshielding effect of about $-36 \mathrm{ppm}$ for the nitrogen atom with respect to a solution in cyclohexane. All these interactions are much larger than those observed for pyrrole-type nitrogens in analogous azole systems. ${ }^{10-13}$

Such observations are in agreement with the predictions made in Scheme 2. The use of Eqn (1) allows us to analyse the complexity of the various solute-solvent interactions and of the relevant responses of the nitrogen shielding, which may vary from a cancellation of large effects to an augmentation and various intermediate possibilities.

To investigate the possible equilibrium of $E-Z$-isomers (Scheme 1) we performed some ab initio molecular orbital 
Table 3. Experimental and $a b$ initio-calculated magnetic shielding of nitrogen in urea systems and in some model compounds and reference substances

\begin{tabular}{|c|c|c|}
\hline Compound & $\begin{array}{l}\text { Experimental NMR shielding } \\
\text { of nitrogen for dilute solutions } \\
\text { in cyclohexane, ref. to neat } \\
\text { liquid nitromethane (ppm) }\end{array}$ & $\begin{array}{l}\text { CHF/GIAO calculated absolute } \\
\text { shielding, } 6-31++\mathrm{G}^{* *} \\
\text { basis set, optimized } \\
\text { geometries (this work) }\end{array}$ \\
\hline \multicolumn{3}{|l|}{$N, N$-Dimethylacetamidine (1) } \\
\hline$=\mathrm{NH}$ & +157.81 & $\begin{array}{l}+42.2(E \text {-isomer })^{\mathrm{a}} \\
+57.9(Z \text {-isomer })\end{array}$ \\
\hline$-\mathrm{NMe}_{2}$ & +311.14 & $\begin{array}{l}+211.7 \text { ( } E \text {-isomer }) \\
+212.9 \text { (Z-isomer })\end{array}$ \\
\hline$N, N$-Dimethylacetamidinium ion & $\begin{array}{l}+260.51 \\
+276.06\end{array}$ & $\begin{array}{l}+166.2\left(\mathrm{NMe}_{2}\right) \\
+176.7\left(\mathrm{NH}_{2}\right)\end{array}$ \\
\hline Pyridine & $+57.70^{\mathrm{b}}$ & $-59.8^{\mathrm{b}}$ \\
\hline Acetone- $N$-methylimine & $+67.93^{c}$ & -46.8 \\
\hline$N, N$-Dimethylacetamide & +288.20 & +195.7 \\
\hline Aniline & +328.60 & +229.8 \\
\hline
\end{tabular}

${ }^{\text {a }}$ The $\mathrm{HF} / 6-31++\mathrm{G}^{* *}$ calculations for optimized geometries show that the $E$-isomer is more stable, by $1.93 \mathrm{kcal} \mathrm{mol}^{-1}$, than the $Z$-form. Hence, the content of the latter should not exceed 5\% if there is any equilibrium between the two forms.

${ }^{\mathrm{b}}$ See Ref. 8; experimental conditions and calculations were the same as those in the present work.

${ }^{\mathrm{c}}$ Experimental data from our earlier work ${ }^{7}$ for a dilute solution in cyclohexane under experimental conditions which were the same as those employed in the present study.

calculations, the results of which are presented in Table 3. We note that the $Z$-isomer is much less stable than the $E$ form. At most, the $Z$-isomer exists to the extent of $5 \%$ in the equilibrium mixture according to the calculations. This conclusion will be corroborated in the discussion of experimental vs calculated nitrogen shieldings. A comparison of the calculated nitrogen shieldings of $\mathbf{1}$ and some model compounds containing amino, amido and imino moieties with the experimental data obtained for dilute solutions in cyclohexane is given in Fig. 1. This shows an excellent correlation given by Eqn (2), with a correlation coefficient of 0.9993 and a standard deviation of $4.50 \mathrm{ppm}$, which amounts to about $1.7 \%$ of the total range of nitrogen shieldings considered (270 ppm):

$$
\sigma_{\text {exp. }}=0.9211 \sigma_{\text {calc. }}+113.06 \mathrm{ppm}
$$

In the plot given by Fig. 1, the calculated values for $\mathbf{1}$ are those for its $E$-isomer. Since the calculated nitrogen shielding differences of the imino moiety of $\mathbf{1}$ for the $E$ - and $Z$-isomers is about $16 \mathrm{ppm}$ (Table 3), the linear correlation would deteriorate significantly if the content of the $Z$-form were appreciable. This is in accordance with the results obtained from the calculations of the energies of the isomers concerned.

In addition to the experimental nitrogen NMR data taken on dilute solutions of $\mathbf{1}$ and the model compounds in cyclohexane which are compared with the nitrogen shielding calculations for isolated molecules, we include in the correlation in Fig. 1 the experimental data for an aqueous solution of $\mathbf{1}$ and the nitrogen shieldings calculated for the corresponding $N, N$-dimethylamidinium ion, i.e. the protonated form of $\mathbf{1},\left[\mathrm{Me}_{2} \mathrm{NC}(\mathrm{Me}) \mathrm{NH}_{2}\right]^{+}$. The assignments of the two nitrogen resonance signals for an aqueous solution are made on the basis of the calculations for the ion concerned. The points obtained are encompassed in the excellent linear correlation given

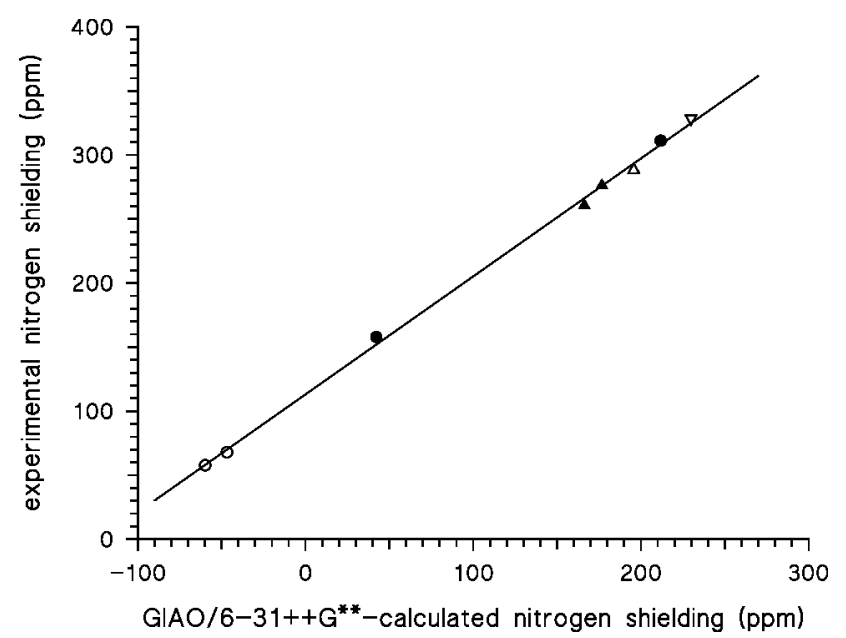

Figure 1. Plot of experimental nitrogen shieldings for $\mathbf{1}$ and some model compounds with respect to external neat nitromethane (bulk susceptibility corrected) against CHF-GIAO/6-31++G**-calculated values with geometry optimization using the same basis set (Table 3). $\bullet, \mathbf{1}$ in a dilute solution in cyclohexane; $\bigcirc$, model imino compounds (pyridine and acetone- $N$-methylimine) in dilute solutions in cyclohexane; $\triangle$, model amino and amido compounds (aniline and $\mathrm{N}, \mathrm{N}$-dimethylacetamide); $\boldsymbol{\Lambda}, 1$ in aqueous solution. The calculated values relate to the corresponding $\mathrm{N}, \mathrm{N}$-dimethylamidinium ion, $\left[\mathrm{MeC}\left(\mathrm{NH}_{2}\right) \mathrm{NMe}_{2}\right]^{+}$.

by Eqn (2). This clearly indicates that in aqueous solution $\mathbf{1}$ is fully protonated.

\section{EXPERIMENTAL}

\section{Materials}

Compound $\mathbf{1}$ was prepared according to a published procedure. ${ }^{19}$ Very pure and dry solvents were used in 
the NMR measurements, as reported previously. ${ }^{7-14}$ The solutions were prepared and handled under a dry argon atmosphere in a glove-box.

\section{Spectra}

The ${ }^{14} \mathrm{~N}$ NMR shielding measurements were made on a Bruker Avance DXR 500 spectrometer system (11.7 T) operating at $36.14 \mathrm{MHz}$ and a temperature of $35 \pm 0.2^{\circ} \mathrm{C}$. Other settings were as follows: $45^{\circ}$ pulse width $10 \mu \mathrm{s}$, acquisition $0.11 \mathrm{~s}$ and exponential filtering matched to nitromethane signal width $(10 \mathrm{~Hz})$, typically about 12000 scans. For the solute nitrogen shieldings in different solvents, the random and systematic errors were reduced to less than $0.1 \mathrm{ppm}$. External neat liquid nitromethane was used as a reference, employing $10 \mathrm{~mm} / 4 \mathrm{~mm}$ coaxial tubes. The inner tube contained a solution of $0.3 \mathrm{M}$ nitromethane in acetone- $d_{6}$. This solution has a nitrogen shielding of $+0.77 \mathrm{ppm}$ from that of neat liquid nitromethane. ${ }^{15}$ This value is obtained from measurements using concentric spherical sample/reference containers to remove bulk susceptibility effects. Hence the inner tube acts not only as a reference with respect to neat liquid nitromethane but also as a deuterium lock for the NMR spectrometer. For the ${ }^{14} \mathrm{~N}$ signal of neat nitromethane, the exact resonance frequency is $36.141524 \mathrm{MHz}$, which gives a value of 36.136826 for the resonance frequency of a bare nitrogen nucleus. ${ }^{15} \mathrm{We}$ employed this value together with the relevant resonance frequency differences to calculate the nitrogen shieldings relative to that of neat nitromethane. Precise resonance frequencies for the external standard and the samples used were obtained by Lorentzian lineshape fitting of the ${ }^{14} \mathrm{~N}$ resonance signals. The relevant linewidths were within the range $10-600 \mathrm{~Hz}$. Since dilute solutions were employed in the present study, it is assumed that their bulk magnetic volume susceptibilites are equal to those of the corresponding solvents at $+35^{\circ} \mathrm{C}$. These susceptibilities were used in calculations of corrections ${ }^{15}$ for bulk susceptibility effects on the apparent shielding differences. The latter corrections ranged from 0 to $1.15 \mathrm{ppm}$ throughout the set of solvents employed. The precision of the shieldings reported in Table 1 is based on the standard deviations of the resonance frequencies obtained in the lineshape fitting procedure and the elimination of systematic errors as described above.

\section{Calculations}

CHF-GIAO $a b$ initio molecular orbital calculations of the nitrogen shieldings were perfomed on a PentiumS (200 MHz)-based system using the Gaussian 94 suite of programs. ${ }^{20}$ Both the full geometry optimization and the nitrogen shielding calculations were performed with a $6-31++\mathrm{G}^{* *}$ basis set of wavefunctions. This set uses both diffuse and polar functions on hydrogen and the heavy atoms concerned and appears to be a satisfactory choice for polar molecules containing lone pairs of electrons.

\section{REFERENCES}

1. González AI, Mó O, Yanéz M, Léon E, Tortajada J, Morizur JP, Leito I, Maria P-C, Gal JF. J. Phys. Chem. 1996; 100: 10490.

2. Oszczapowicz J, Kumińska M. J. Chem. Soc. Perkin Trans. 2 1994; 103.

3. Oszczapowicz J, Jaroszewska-Madaj J, Ciszkowski K. Pol. J. Chem. 1993; 67: 2159.

4. Wawer I. Magn. Reson. Chem. 1989; $27: 577$.

5. Raczyńska ED, Laurence C. J. Chem. Res. (S) 1989; 148.

6. Bureiko SF, Chernyshova IV. J. Mol. Struct. 1991; 263: 37.

7. Witanowski M, Sicinska W, Webb GA. Spectroscopy Int. J. 1992; 10: 25 .

8. Witanowski M, Sicinska W, Biernat S, Webb GA. J. Magn. Reson. 1991; 91: 289.

9. Witanowski M, Biedrzycka Z, Sicinska W, Grabowski Z, Webb GA. J. Magn. Reson. (A) 1997; 124: 127.

10. Witanowski M, Sicinska W, Grabowski Z, Webb GA. J. Magn. Reson. (A) 1993; 104: 310.

11. Witanowski M, Sicinska W, Biedrzycka Z, Webb GA. J. Magn. Reson. (A) 1994; 109: 177.

12. Witanowski M, Sicinska W, Biedrzycka Z, Grabowski Z, Webb GA. J. Magn. Reson. (A) 1995; 112: 66.

13. Witanowski M, Biedrzycka Z, Sicinska W, Grabowski Z. J. Magn. Reson. 1998; 131: 54.

14. Witanowski M, Sicinska W, Biedrzycka Z, Webb GA. J. Mol. Struct. 1997; 404: 267.

15. Witanowski M, Stefaniak L, Webb GA. Annu. Rep. NMR Spectrosc. 1993; 25: 1-480, and references cited therein.

16. Abraham MH, Grellier PL, Abboud JLM, Doherty RM, Taft RW. Can. J. Chem. 1988; 66: 2673.

17. Marcus Y. Chem. Soc. Rev. 1993; 409.

18. Weast RC (ed). Handbook of Chemistry and Physics (64th edn). Chemical Rubber Co.: Cleveland, OH, 1984; E-49.

19. Neuman RC, Young LB. J. Phys. Chem. 1965; 69: 2570.

20. Frisch MJ, Trucks GW, Schlegel HB, Gill PMW, Johnson BG, Robb MA, Cheeseman JP, Keith T, Petersson GA, Montgomery JA, Raghavachari K, Al-Laham MA, Zakrzewski VG, Ortiz JV, Foreman JB, Cioslowski J, Stefanov BB, Nanayakkara A, Challacombe M, Peng CY, Ayala PY, Chen W, Wong MW, Andres JL, Replogle ES, Gomperts R, Martin RL, Fox DJ, Binkley JS, Defrees DJ, Baker J, Stewart JP, Head-Gordon M, Gonzalez C, Pople JA. Gaussian, Inc., Pittsburgh, PA, 1995. 